\title{
Harmonic Mitigation in Distribution System by using Passive Filters
}

\author{
Nyein Nyein Chan ${ }^{1}$, Hnin Wai Hlaing ${ }^{2}$ \\ ${ }^{1}$ Assistant Lecture, ${ }^{2}$ Professor \\ Department of Electrical Power Engineering, Technological University Thanlyin, Thanlyin, Myanmar
}

\begin{abstract}
The advent of power electronics and computerized equipment in recent decades has brought enhanced efficiency and improved system but at the same time also created harmonics and waveform distortion to the power system network. Due to the growing use of nonlinear load equipment and new technologies in buildings, harmonic currents and voltages generated in distribution systems pose a new problem for electrical engineers. This is a serious problem when power quality is a prime concern. Harmonics are the main types of power quality problem that are very common to the power system containing electric arc furnace (EAF). Electric arc furnace (EAFs) are widely used in steelmaking and in melting of nonferrous metals. In this paper, EAF is presented guide lines for the accurate evaluation of harmonics generated in No.(3) Steel Mill, Ywama, Yangon. Passive filters have been most commonly used to limit the flow of harmonic currents in distribution systems. Their performance is limited to a few harmonics, and they can introduce resonance in the power system.
\end{abstract}

KEY WORDS: Simulation by Using Matlab Software, Passive Filters, Nonlinear Load, Total Harmonic Distortion, Electric Arc Furnace, IEEE Std 519-1992.

\section{INTRODUCTION}

Harmonics are a mathematical way of describing distortion to a voltage or current waveform. The term harmonic refers to a component of a waveform that occurs at an integer multiple of the fundamental frequency [1]. And the objective of the electric utility is to deliver sinusoidal voltage at fairly constant magnitude throughout their system. There are nonlinear loads on the system that produce harmonic currents. These non-linear elements generate network voltages with frequencies different from the network frequency or absorb currents with non-sinusoidal waveforms. The widespread and growing of these loads has greatly increased the flow of harmonic currents on facility distribution systems. The interest on problems related to non linear devices and their influence on the systems increased considerably since 1980. This is due to the development of new power semiconductor devices and, as a consequence, the development of new converters that affects linearity in electric power signals substantially. The increase on the utilization of electronic equipment modified the sinusoidal nature of electrical signals. These equipments increase the current waveform distortion and as a consequence, increment the voltage waveform distortion [2] [3].

The electric arc furnace is either AC or DC operated. It transfer the electric energy (electric arc) to melt the scrap material held by the furnace. The arc produced between the electrodes low voltages and high current supplied by the furnace transformer. [5].

\section{PRINCIPLE OF ARC FURNACE OPERATION}

The operation of electric arc furnace can be divided in into intervals namely melting and refining periods. The refining period is further divided in several stages. During the melting stage, the electrode is lowered through a hydraulic actuator system to maintain the stable arc. The furnace draws active power in this condition. More and more buckets of scrap material are added into the furnace during the melting stages. During the refining stage, a long arc is established. The factors involved during the operation of the furnace are electrode position, electrode arm control scheme, supply voltage, operation reactance and the materials used for melting and refining. The installations of both $\mathrm{AC}$ and DC electric arc furnace [4] have been shown in figure.1(a) and 1(b) respectively as shown. 


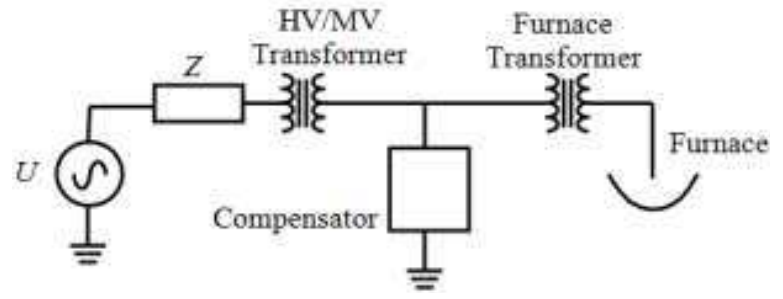

Figure 1(a) Installation of AC Arc Furnace

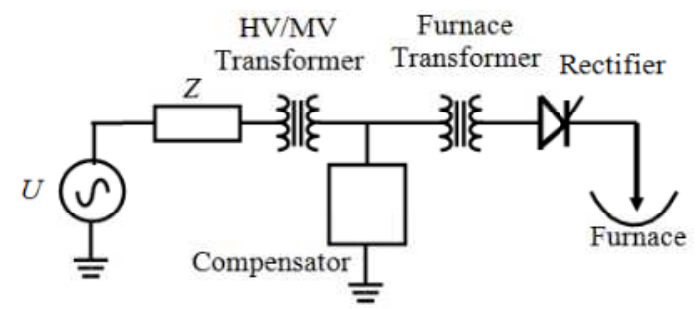

Figure 1(b) Installation of DC Arc Furnace

A transformer directly energizes furnace electrodes in a high current circuit in AC arc furnace, whereas DC furnace employ a controlled rectifier to supply dc to the furnace electrodes. Arc furnace operation may be classified into stages, depending on the status of the melt and the time lapse from the initial energizing of the unit. During the melting period, pieces of steel create momentary short circuits on the secondary side of the furnace transformer. These load changes effect the arc characteristics, causing fluctuations of current. The current fluctuations cause variations in reactive power, which cause a momentary voltage drop or flicker, both at the supply bus and at nearby buses in the interconnected system. The arc currents are more uniform during the refining period and result in less impact on the power quality of the system. Arc furnaces also create harmonic load currents and asynchronous spectral components. Harmonics represent an important power quality issue, because they may cause undesirable operating conditions.

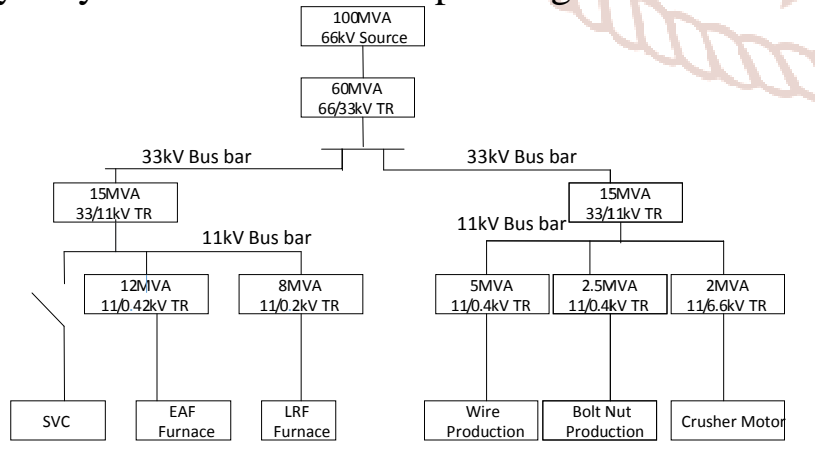

Index: $\quad$ TR =Transformer

Figure.2 Complete Model of No (3) Ywama Steel Mill

\section{VOLTAGE AND CURRENT HARMONIC LIMITS}

According to IEEE Std 519-1992, harmonic voltage distortion on power system $69 \mathrm{kV}$ and below is limited to $5.0 \%$ total harmonic distortion (THD) with each individual harmonic limited to $3 \%$. The current harmonic limits vary based on the short circuit strength of the system they are being injected into. Essentially, the more system is able to handle harmonic currents, the more the customer is allowed to inject [6].

\section{Table .1 IEEE Std 519-1992 Harmonic Voltage Limits Voltage Distortion Limits}

\begin{tabular}{|c|c|c|}
\hline $\begin{array}{c}\text { Bus Voltage at } \\
\text { PCC }\end{array}$ & $\begin{array}{c}\text { Individual } \\
\text { Voltage } \\
\text { Distortion }(\%)\end{array}$ & $\begin{array}{c}\text { Total Voltage } \\
\text { Distortion } \\
\text { THD }_{\mathrm{V}}(\%)\end{array}$ \\
\hline Below 69kV & 3.0 & 5.0 \\
\hline $69 \mathrm{kV}$ to $161 \mathrm{kV}$ & 1.5 & 2.5 \\
\hline $\begin{array}{c}161 \mathrm{kV} \text { and } \\
\text { above }\end{array}$ & 1.0 & 1.5 \\
\hline
\end{tabular}

Table .2 IEEE Std 519-1992 Harmonic Current Limits

Current Distortion Limits for General Distribution Systems (120V Through 69kV)

Maximum Harmonic Current Distortion in Percent of IL

Individual Harmonic Order ( Odd Harmonic )

\begin{tabular}{|c|c|c|c|c|c|c|}
\hline $6=\mathrm{I}_{\mathrm{SC}} / \mathrm{I}_{\mathrm{L}}$ & $<11$ & $\begin{array}{c}11- \\
16\end{array}$ & $\begin{array}{c}17- \\
22\end{array}$ & $\begin{array}{c}23- \\
35\end{array}$ & $>35$ & $\mathrm{TDD}$ \\
\hline$<20$ & 4.0 & 2.0 & 1.5 & 0.6 & 0.5 & 5.0 \\
\hline $20<50$ & 7.0 & 3.5 & 2.5 & 1.0 & 0.5 & 8.0 \\
\hline $50<100$ & 10.0 & 4.5 & 4.0 & 1.5 & 0.7 & 12.0 \\
\hline $100<1000$ & 12.0 & 5.5 & 5.0 & 2.0 & 1.0 & 15.0 \\
\hline$>1000$ & 15.0 & 7.0 & 6.0 & 2.5 & 1.4 & 20.0 \\
\hline
\end{tabular}

\section{HARMONIC FILTERS}

Harmonics currents are created by nonlinear loads that generate non-sinusoidal current on distribution power system. Nonlinear devices such as power electronics converters can inject harmonics alternating currents (AC) in the electrical power system. Therefore, the growing use of nonlinear loads in commercial, residential and industrial are becoming more harmonic problems at utilities and customers sides. Harmonics are the most important drawbacks of power quality in the power distribution system. With the increase of nonlinear loads in the power system, more and more harmonic mitigation techniques are required. There are three types of filter 
1. Passive Filters

2. Active Filters

3. Hybrid Filters [8][9].

Passive Filters:

Passive filters are basically topologies or arrangements of $\mathrm{R}, \mathrm{L}$, and $\mathrm{C}$ elements connected in different combinations to gain desired suppression of harmonics. They are employed either to shunt the harmonic currents off the line or to block their flow between parts of the system by tuning the elements to create a resonance at a selected frequency. They also provide the reactive power compensation to the system and hence improve the power quality. However, they have the disadvantage of potentially interacting adversely with the power system and the performance of passive filter depends mainly on the system source impedance. On the other hand they can be used for elimination of a particular harmonic frequency, so number of passive filters increase with increase of harmonics on the system.

They can be classified into:

1. Passive Shunt Filter

2. Passive Series Filter

a. i. Passive Shunt Filter connection. A passive type series passive filter has property of purely inductive type or LC tuned characteristics. The main component of passive series filter in $\mathrm{AC}$ line reactor and DC link filter.

\section{SIMULATION MODELS AND RESULTS}

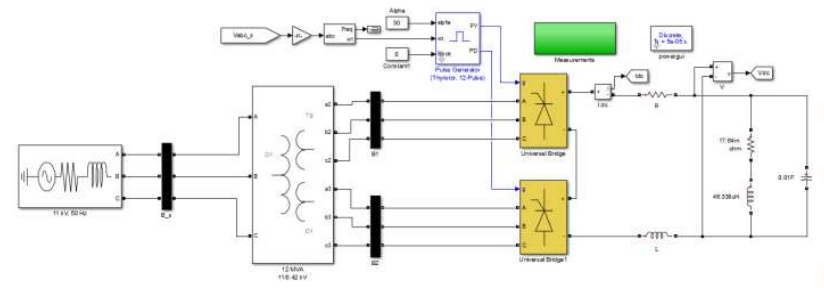

Figure .5 Simulation Model of Electric Arc Furnace without Filter in No.(3) Ywama Steel Mill

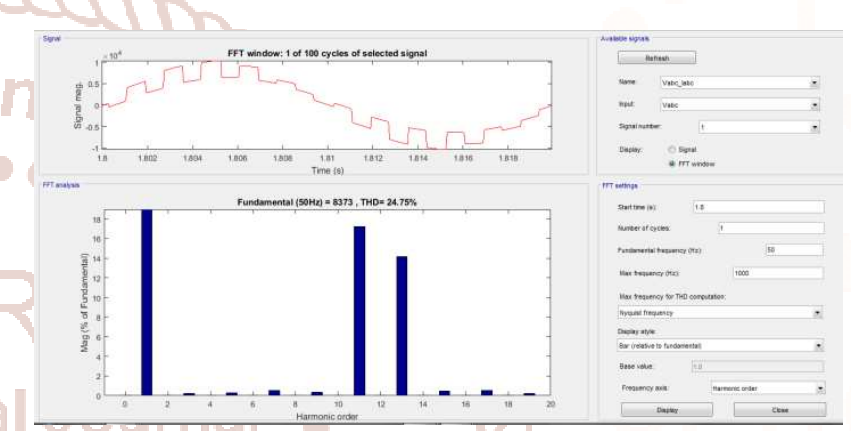

Figure.6 Total Harmonic Distortion Voltage Waveform without Filter for EAF with Bar (relative to fundamental)

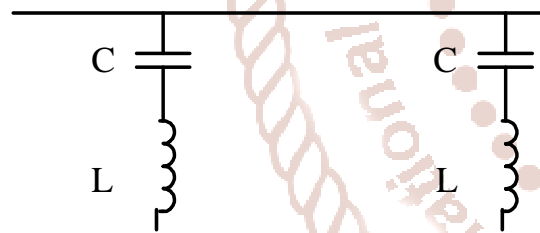

Figure .3 Shunt filter connection
Passive filters are connected in parallel with the system. Figure .3 illustrates the parallel passive filter connection. The shunt may be grounded in one of its terminations, and then it will be passed only for the tuned harmonic current and a part of the fundamental current. The passive shunt type filter is that it only carry fraction of current so the whole system AC power losses are reduced compare to series type filter.

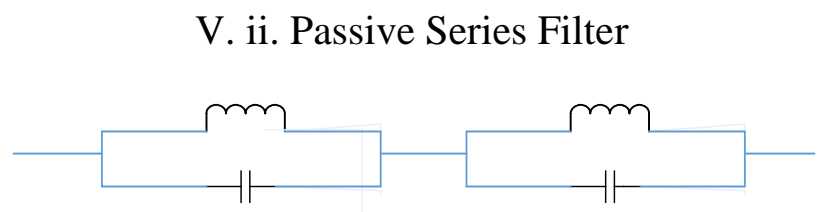

Figure .4 Series filter connection

Passive filters are connected in series with the system. Figure .4 illustrates the series passive filter
Figure.7 Total Harmonic Distortion Voltage Waveform without Filter for EAF with List (relative to fundamental)

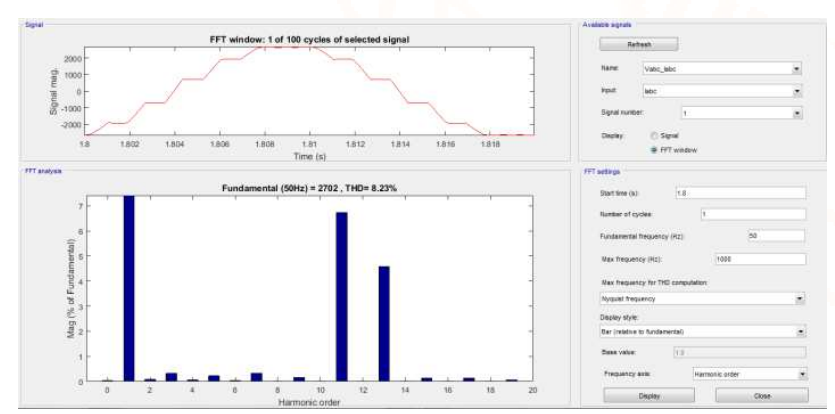

Figure.8 Total Harmonic Distortion Current Waveform without Filter for EAF with Bar (relative to fundamental) 

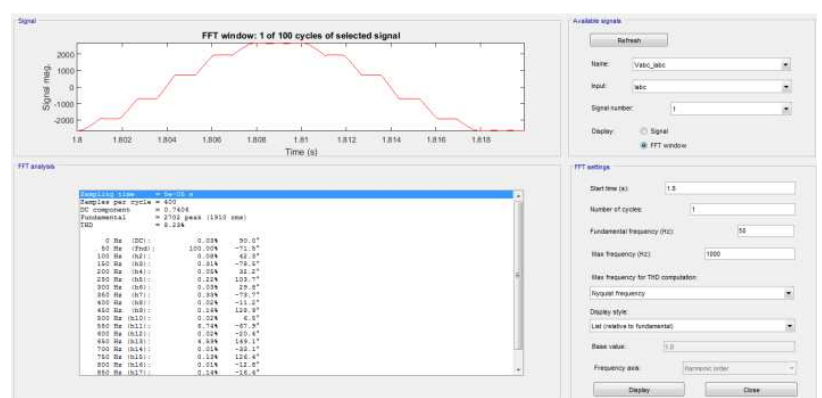

Figure.9 Total Harmonic Distortion Current Waveform without Filter for EAF with List (relative to fundamental)

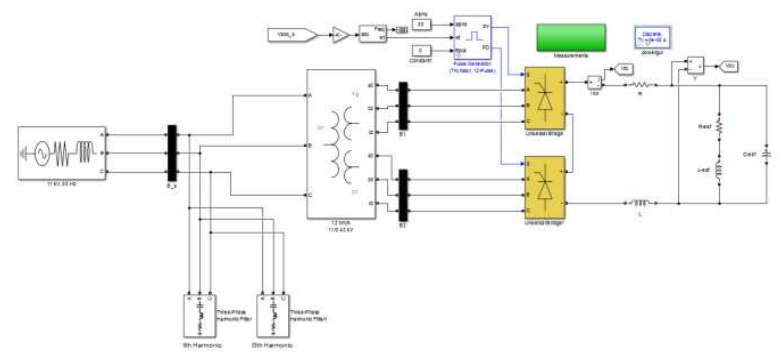

Figure.10 Simulation Model of Electric Arc Furnace with Passive Filter (PF)
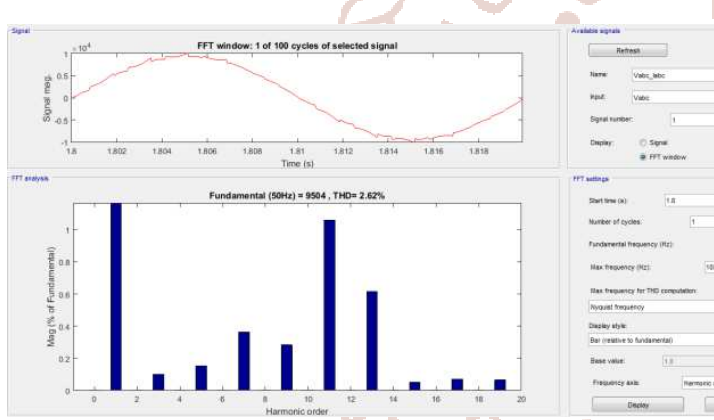

Figure.11 Total Harmonic Distortion Voltage Waveform with PF for EAF with Bar (relative to fundamental)

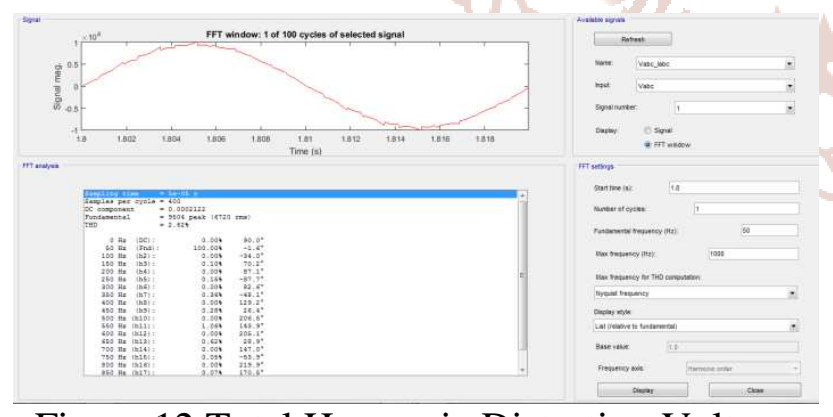

Figure.12 Total Harmonic Distortion Voltage Waveform with PF for EAF with List (relative to fundamental)

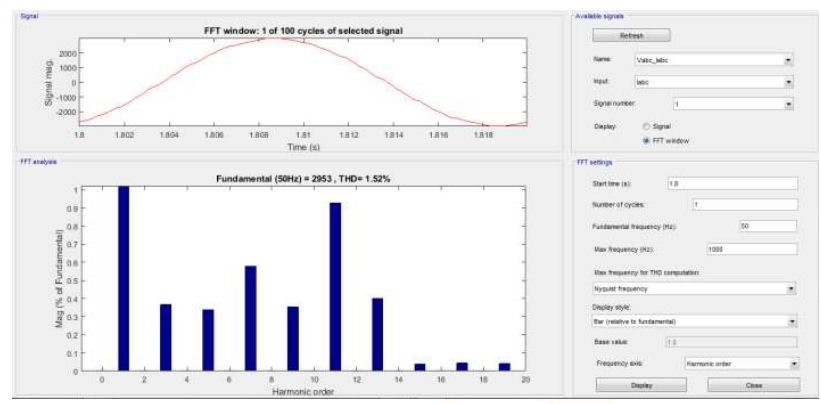

Figure.13 Total Harmonic Distortion Current Waveform with PF for EAF with Bar (relative to fundamental)

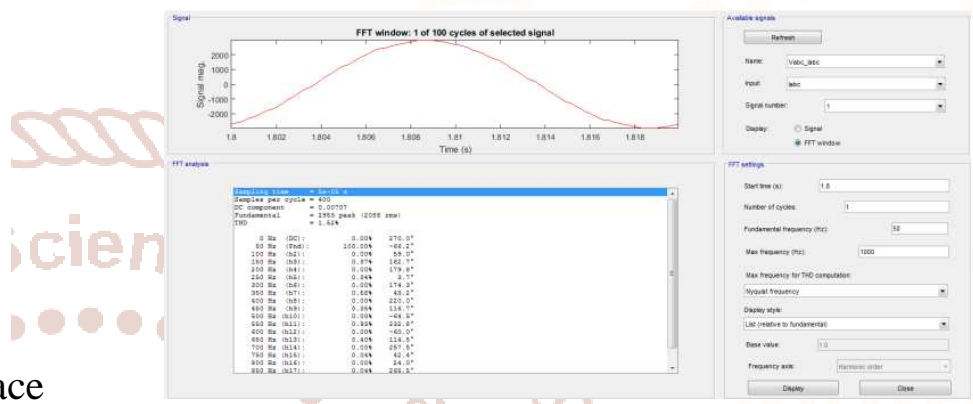

Figure.14 Total Harmonic Distortion Current Waveform with PF for EAF with List (relative to fundamental)

Table. 3 Comparison of Total Harmonics Voltage \& Current Distortion \% without and with PF

\begin{tabular}{|c|c|c|}
\hline System & THDV $_{\text {V }}(\%)$ & THD $_{\text {I }}(\%)$ \\
\hline Without Filter & $24.73 \%$ & $8.26 \%$ \\
\hline With Passive Filter & $2.62 \%$ & $1.52 \%$ \\
\hline
\end{tabular}

VI. CONCLUSION AND FUTURE SCOPE

The new block developed proved to be effective in harmonic distortion analysis in a steel plants as carried out in this paper. Here the total harmonic distortion (THD) was measured by the THD block in Simulink. The distortion for both voltage and current due to the steel plant were excessive and could be mitigated using passive filter of commensurable design in proposed. According to the simulation results above the figures, the $\mathrm{THD}_{\mathrm{V}}(\%)$ is $24.73 \%$ and THDI $(\%)$ is $8.26 \%$ at the point of common coupling (PCC) without using the mitigation techniques in present conditions. The harmonic twenty orders are measured and among them, $11^{\text {st }}$ and $13^{\text {th }}$ orders are dominant in No.(3) Steel Mill (Ywama, Yangon). After using the passive harmonic filters, the $\mathrm{THD}_{\mathrm{V}}$ is $2.62 \%$ and $\mathrm{THD}_{\mathrm{I}}$ is $1.52 \%$ of the fundamental value, thus meeting the limit of harmonic standard of IEEE Standard 519-1992. The future work is harmonic mitigation in distribution system by using active and hybrid harmonic filters. 


\section{ACKNOWLEDGMENTS}

I greatly appreciate to all teachers from the Department of Electrical Power Engineering, Technological University (Thanlyin) who work in Research.

I would like to give great thanks to Research Department of Electrical Power Engineering, Technological University (Thanlyin) for kind permission to study related on-going research projects.

\section{REFERENCES}

1. Ashok, S. "Harmonic in distribution system of an educational institution" IEEE transactions on power quality 98 pages 145-150, 1998.

2. Alejandro O.M. and Gustavo A.R. "Instantaneous $\mathrm{p}$-q theory for harmonic compensation via shunt active power filter" IEEE transactions on power electronics and power quality applications, page 1-4, 2013.

3. Jamil M. "Harmonics in Adjustable Speed Drives" IEEE transactions on information and emerging technologies, page 1-6, 2007.
4. Reuben F. Burch IV, Senior Member, IEEE "Thoughts on Improving the Electric Arc Furnace Model".

5. Amarjeet Singh, Ravindra Kumar Singh, Asheesh Kumar Singh "Power Quality Issue of Electric Arc Furnace and their Mitigations - A Review", ISSN: 2349-6495(p) 2456-1908(O), Vol-4, Issue4, Apr-2017.

6. Thomas M. Blooming, P.E, Daniel J. Carnovale P.E. "Application of IEEE Std 519-1992 Harmonic Limits".

7. Rooh UI Amin Shaikh, Abdul Basit Lashari, Irfan Ansari, "Harmonic Analysis and Mitigation Using Passive Filters" January, 2015.

8. Rustemli, S. and Cengiz, M.S. 2016, "Passive Filter Solution and Simulation Perfornance in Industrial Plants". Bitlis Eren University J Science and Technology, Turkey.

9. Nassif, A.B., Xu, W. and Freitas, W.2009, “An Investigation on the Selection of Filter Topologes for Passive Filter Applications". IEEE PES General Meeting, 2009.

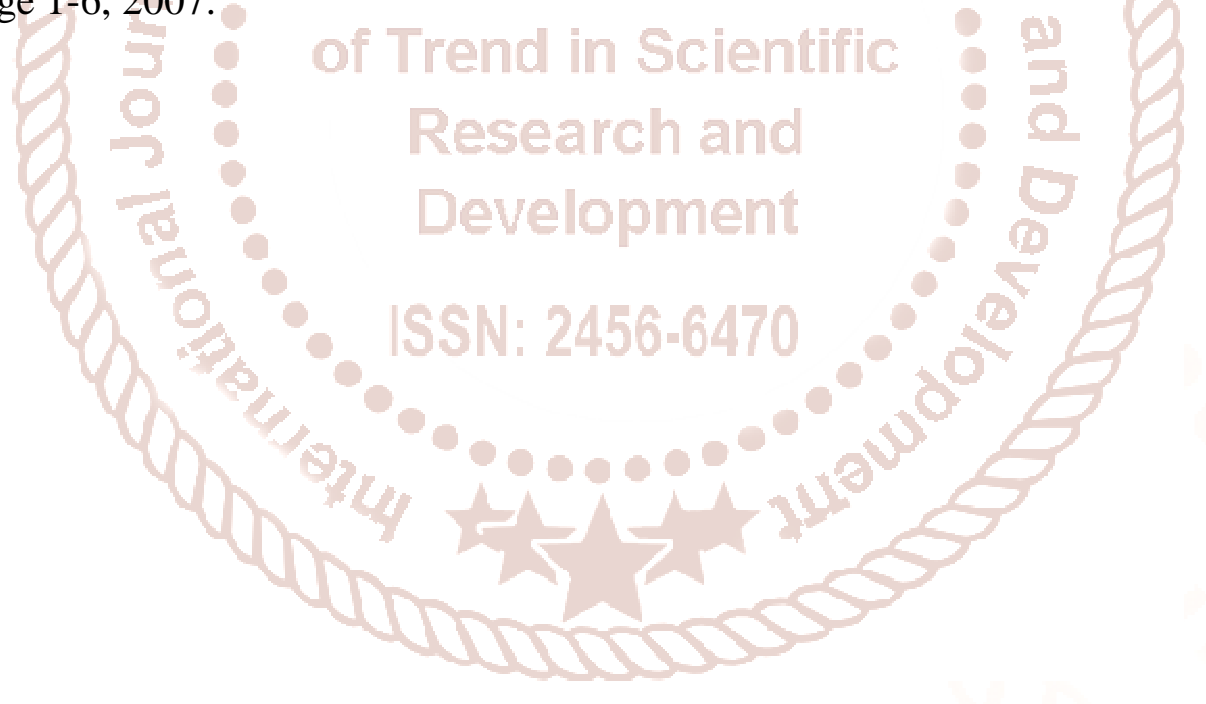

